\title{
La gimnasia estética de grupo, un nuevo modelo de competición
}

\section{The Aesthetic group gymnastics, a new model of competition}

Conesa, E. y Martínez-Gallego, F.Ma .

Facultad de Ciencias del Deporte. Universidad de Murcia, España

\begin{abstract}
Resumen: El propósito de este trabajo es realizar una revisión bibliográfica sobre los orígenes históricos, las características técnicas y los aspectos claves del reglamento de una modalidad deportiva relativamente desconocida y novedosa como es la Gimnasia Estética de Grupo (GEG). En este contexto, la GEG originaria de los países nórdicos, especialmente Finlandia y Suecia en el siglo XVIII, sirve a la sociedad para motivar especialmente a las mujeres a la práctica de actividad física y mantenerla en el tiempo. Aún está vigente esta llamada, y desde hace unos 10 años se introdujo en nuestro país existiendo un incremento considerable en la práctica de la misma entre la población infantil y juvenil femenina. Se implanta en Espańa atendiendo a las exigencias estrictas del Reglamento Internacional, que priman los aspectos saludables. La GEG se define como una disciplina deportiva basada en el movimiento estilizado y natural del cuerpo, que combina y realza cualidades como el dinamismo, el ritmo y la armonía de los movimientos realizados con el uso económico y natural de la fuerza. Es expresión, arte y sentimiento convertido en deporte de competición. Todo ello, realizado por un grupo de deportistas del que fluye un movimiento estético y sincronizado. Analizaremos su técnica y se detallarán las características más importantes de este deporte que lo lleva a diferenciarse de la gimnasia rítmica deportiva. Palabras claves: Rítmica, danza, expresión corporal, aspectos saludables, reglamento.
\end{abstract}

Abstract: The purpose of this study is to review the literature on the historical origins, the technical characteristics and the key aspects of the regulation of a new and relatively unknown sport; the Aesthetic Group Gymnastics (GEG). This sport, which origin is in the Nordic countries, especially Finland and Sweden in the 18th century, serves the society to especially encourage women to physical activity and maintain it over time. This call is still in force, and for about 10 years was introduced in our country and there is a considerable increase in the practice of the same among the female children and adolescents. This sport is implanted in Spain in response to the strict requirements of the International Regulations that gives priority to the health aspects. The GEG is defined as a sport based on the stylized and natural body movement, which combines and enhances qualities like dynamism, rhythm and harmony of movements performed with economic and natural use of force. It is an expression, art and feeling become competitive sport. All of this done by a group of athletes flowing aesthetic and synchronized movement. We analyse the technique and the most important characteristics of this sport that allows to understand the differences between itself and the rhythmic gymnastics.

Keywords: rhythmic, dance, movement, health aspects, regulation.

\section{Contextualización histórica}

La gimnasia tiene sus orígenes en la antigua Grecia, donde predomina el concepto de desarrollo del cuerpo a través del movimiento natural, si bien no es hasta el comienzo del siglo XIX cuando se inician los orígenes de nuestra actual gimnasia. A partir de 1800 evoluciona el deseo de realizar una nueva actividad física, que comienza a desarrollarse con las diferentes escuelas europeas, volviéndose a considerar los aspectos estéticos y educativos de la gimnasia. Estas escuelas se fundaron sobre métodos específicos que permitían formar físicamente con movimientos expresivos a las mujeres, y aún hoy, la gimnasia sigue sirviendo en la sociedad como motivadora para el género femenino y para mantener esa práctica en el tiempo (Kleenola, 1996).

En la actualidad el aumento de horas de trabajo y estudio, comienza a provocar inmovilidad y actitudes posturales viciosas, que incrementan los defectos y las enfermedades propias de la vida sedentaria. La gimnasia ha logrado imponerse no sólo como estructura educativa de primer orden,

Dirección para correspondencia [Correspodence address]: Elena Conesa Facultad de Ciencias del Deporte. Universidad de Murcia. (Espańa). E-mail: econesaros@um.es sino también como actividad individual y válida por sí misma. Diferentes formas de trabajo de los ejercicios gimnásticos aparecen entre 1800 y 1936 (Langlade y Langlade, 1986). En ese periodo, se inician tres grandes movimientos gimnásticos simultáneamente: el Movimiento del Oeste (Francia), el Movimiento del Centro (Alemania, Austria y Suiza) y el Movimiento del Norte (Escandinavia) (Langlade y Langlade, 1986).

Es el Movimiento del Norte el que cobra más importancia en la presente investigación. Gran parte de la gimnasia surge de un sistema sueco de ejercicio libre impartido por Pedro Ling para la capacitación física del ejército. Dulcificando este método, alumnas de la teoría de Ling promueven la "Gimnasia Estética”, en la que los alumnos expresan sus sentimientos y emociones a través del movimiento corporal. Destaca también Dalcroze (1865-1950), el cual desarrolla una forma de entrenamiento físico para los músicos y bailarines en el que conjuga la música con el movimiento desarrollando el sentido del ritmo y la expresión (Rodríguez Abreu, 2010) con el nacimiento de la gimnasia moderna (Gimnasia Rítmica Femenina). Esta actividad vio sus primeros intentos en el período de la I Guerra Mundial (1914-1918), pero no fue hasta el verano 
de 1951 cuando se popularizó, al crearse la Liga internacional de la Gimnasia Moderna, fundándose oficialmente el 9 de febrero de 1952, en Frankfort (Alemania), con la escuela alemana. Allí encontramos a Guts Muths (1750-1839) al que se conoce como padre de la gimnasia pedagógica, el principal contribuyente de las diferentes modalidades gimnásticas.

Los orígenes de la gimnasia moderna recibieron también las aportaciones de J.G. Noverre (1727-1809), coreógrafo original que devuelve al bailarín su condición expresiva y a Francois Delsarte (1811-1871) cuyas obras constituyen la base de la teoría del movimiento expresivo e influyen en el desarrollo de la pantomima, el ballet y la gimnasia.

Otros que influyeron en un alto grado en la evolución de la gimnasia femenina fueron Isadora Duncan (1878-1927) quien con su expresión de sentimientos y naturalismo basado en el amor a la naturaleza contribuyó a que en muchos países, incluida Rusia, surgieran estudios de Gimnasia Rítmica y Estética. Henrich Medau (1890-1974) fundó la Escuela Medau en Berlín para formar a los gimnastas en la "Gimnasia Moderna” y para desarrollar el uso de los aparatos gimnásticos. Posteriormente, fue la canadiense Evelyn Koop quien introdujo la Gimnasia Rítmica Deportiva en nuestro continente. Hilma Jalkanen (1889-1964) incorpora elementos de danza y movimientos expresivos en una escuela finlandesa nueva de la gimnasia. Esta última, introdujo un nuevo aire a las teorías de Ling dentro del movimiento de la gimnasia "neo sueca", presentando a la "Gimnasia Estética" como dulcificación del estilo militar que caracterizaba a la gimnasia masculina de la época, introduciendo movimientos corporales naturales acompasados con música.

Con este nuevo modelo de gimnasia, Elin Falk (Langlade y Langlade, 1986) es la primera que se preocupó por la formación y corrección de la postura y aportó a la técnica las primeras posiciones "aisladoras", que surgieron de la observación de las niñas de las Escuelas Primarias de Estocolmo, advirtiendo que al ejecutar ciertos ejercicios aumentaban su curvatura lumbar. Estas contribuciones han repercutido en la actualidad en la gimnasia mundial. En estas escuelas se utiliza el valor de los gestos naturales que implican a todo el cuerpo, con movimientos fluidos y rítmicos, en contra de los movimientos artificiales.

Por otro lado, se encuentra la gimnasia escolar austriaca, también denominada gimnasia natural, en la que el norteamericano Winslow Taylor (1856-1915), aporta sus conceptos de economía en el esfuerzo, luchando en contra de los movimientos artificiales, empleando movimientos fluidos y rítmicos (figura 1).

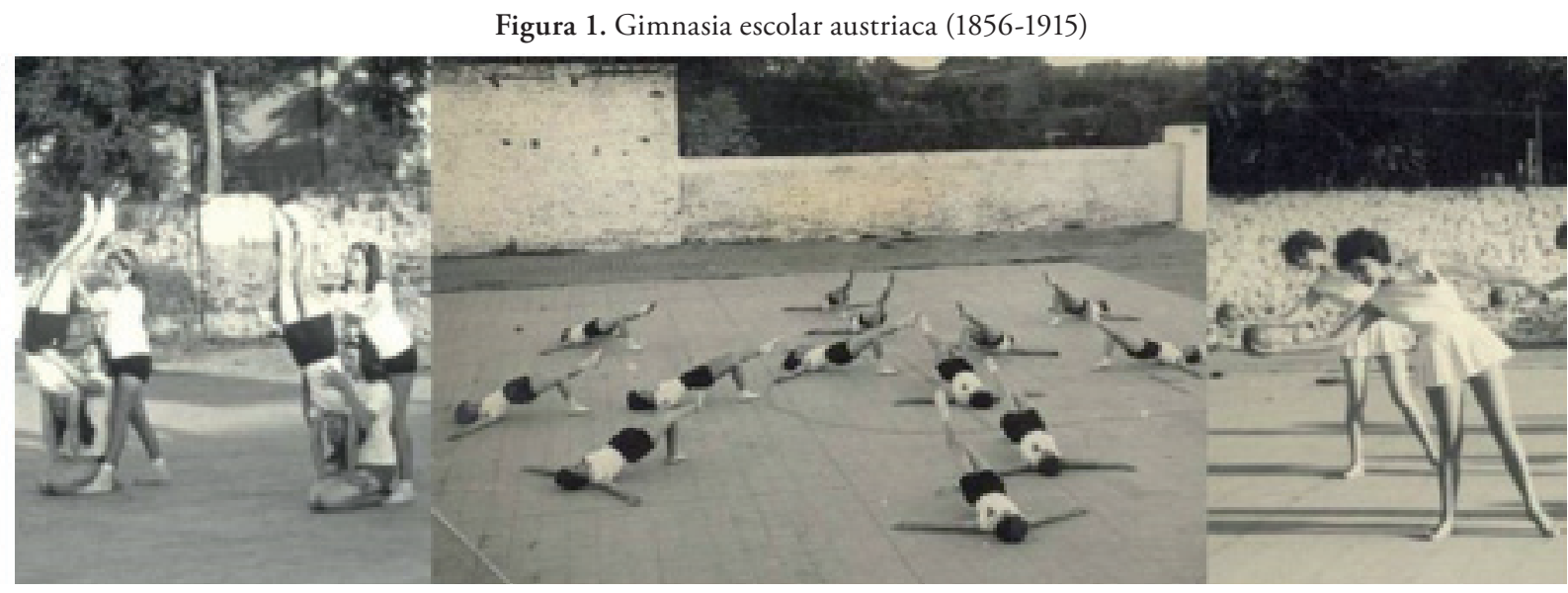

En 1996, la Gimnasia Estética de Grupo fue reconocida internacionalmente como un deporte de competición. En 2003, se crea la Federación Internacional de GEG para la expansión y promoción de este deporte en rendimiento a nivel internacional (IFAGG, 2012).

La Federación Internacional de GEG proporciona liderazgo, sistemas y programas para todos los miembros, con el objetivo de:

1) Promover el deporte de la GEG;

2) Coordinar las competiciones y eventos internacionales;

3) Conceder el derecho a organizar los Campeonatos del Mundo;
4) Desarrollar y mantener las normas internacionales de la GEG;

5) Desarrollar materiales de capacitación y programas educativos para entrenadores y jueces;

6) Fomentar las relaciones de cooperación con otras organizaciones deportivas internacionales;

7) Representar los intereses de GEG en todo el mundo cuando se trata de otras organizaciones.

Países europeos como Finlandia y Estonia, llevan practicando y promocionando este deporte desde hace más de 100 años como filosofía y hábito de vida y se han desarrollado competi- 
ciones desde la década de los 50 del pasado siglo. En sus inicios se le denominó "Gimnasia para mujeres" por el movimiento femenino y armónico que le caracteriza (Sierra, 2008).

La primera competición oficial se celebró en Helsinki (Finlandia) en 1996 y en junio de 2000 se celebró el primer Campeonato del Mundo también en esa ciudad. Los índices de participación en los Campeonatos del mundo prevén un brillante futuro para este deporte de reciente creación en el ámbito de la gimnasia de competición internacional (IFAGG, 2012).

En un principio participaban unos 10 países pero este número ha ido aumentando cada ańo con la incorporación de nuevos países como España, que participó en el 2004 por primera vez. De esta forma se ha conseguido la implantación en quince países. Al igual que España, países europeos como Francia, Italia y Alemania empiezan a interesarse por esta disciplina.

En Espańa, el primer club espańol se formó a finales de enero de 2004, el club AEGEG (Asociación Española de Gimnasia Estética de Grupo), en el INEF de Barcelona, debutando en el Campeonato del Mundo celebrado en Bulgaria ese mismo año. Al mismo tiempo que el club, se fundó con el mismo nombre la AEGEG, Asociación Española de Gimnasia Estética de Grupo. Después de la participación en el primer mundial, el objetivo principal de esta asociación ha sido difundir este deporte por toda España. Para conseguir este propósito se han realizado diversas exhibiciones en lugares como el Instituto Nacional de Educación Física (INEF) y en el "Fòrum de les Cultures" y se llevaron a cabo entrenamientos abiertos a otras entrenadoras que quisieran iniciarse en este nuevo deporte; también se han realizado cursos para entrenadoras y jueces nacionales e internacionales (Sierra, 2008). La espectacularidad de este deporte le augura un gran futuro, habiéndose extendido con gran rapidez su práctica por el territorio nacional en tan solo 10 ańos desde que se comenzó a practicar en nuestro País. En año 2012 se celebró el Campeonato del Mundo en Cartagena (figura 2).

Figura 2. Campeonato del Mundo de Gimnasia Estética de Grupo celebrado en Cartagena en 2012.

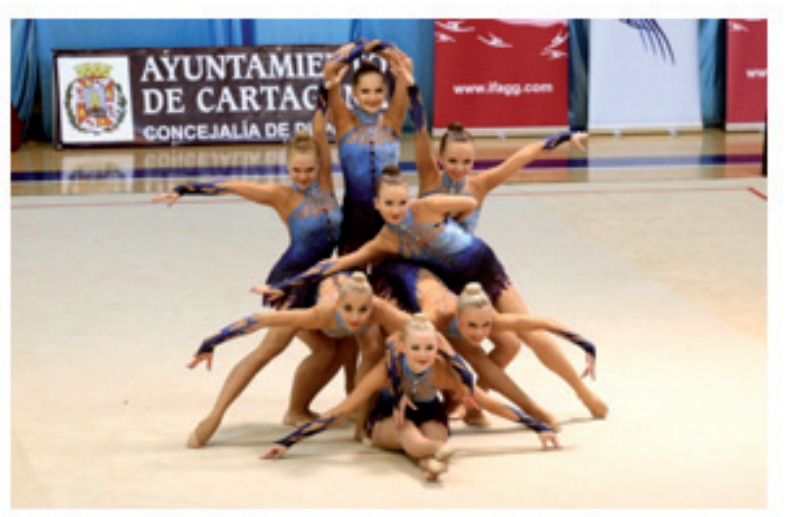

\section{Aproximación conceptual}

Actualmente la sociedad considera al deporte como un valor que repercute en la prevención de la salud y en la estética corporal (Barreto, 2006; Devís, 2000). La GEG es una disciplina deportiva muy reciente, sobre todo como deporte de competición. Esto trae como consecuencia la escasez de bibliografía o estudios con mayor o menor rigor científico sobre ella. Tenemos por ello que limitarnos a lo recogido en el Reglamento deportivo de puntuación en su versión más reciente para indagar sobre el significado de la GEG (Sierra, 2008).

Las normas de competición y práctica se especifican en el Reglamento Internacional. Éste puede definirse como el conjunto de reglas y normas que regulan los diferentes factores que constituyen la estructura de los ejercicios de competición y en consecuencia la lógica interna de los mismos, es decir la relación de la gimnasta con sus compañeras, con el espacio y con el tiempo. En la Gimnasia Estética de Grupo, la aplicación de este reglamento de puntuación a las situaciones de competición y a las acciones de los gimnastas, se hace a partir del criterio de un grupo de jueces. Los diferentes jurados en los que se divide la competición, recogen las reglas específicas para valorar la práctica saludable y las penalizaciones que conlleva su falta (Conesa, 2015).

Dicho Reglamento permite una aproximación clásica a la GEG como deporte y hasta ahora ha sido el documento que ha servido como punto de partida y valor referencial para analizar las diferentes características de este deporte, tanto para jueces, entrenadores o educadores. El reglamento no se limita a la función de normativizar la práctica, sino que supone un compendio de carácter técnico preceptivo en el ámbito de la salud y la práctica deportiva.

La GEG se define como una disciplina deportiva basada en el movimiento estilizado y natural del cuerpo, que combina y realza cualidades como el dinamismo, el ritmo y la armonía de los movimientos realizados con el uso económico y natural de la fuerza. Es expresión, arte y sentimiento convertido en deporte de competición. Todo ello, realizado por un grupo de deportistas del que fluye un movimiento estético y sincronizado (IFAGG, 2012).

La actividad deportiva de GEG a nivel de competición, empieza a la edad de 8 años. Está basada en la "combinación de arte coreográfico, el desarrollo muscular armónico y la naturalidad de hábitos motrices saludables”. Es una gimnasia estilizada, cuya técnica se centra en el aprendizaje de movimientos naturales del cuerpo, donde las caderas son el centro básico del mismo. Se realiza en grupos de 6 a 12 gimnastas (categorías junior y senior) o de 6 a 14 gimnastas (categoría Infantil), pudiendo participar tanto mujeres como hombres. Los gimnastas evolucionan sobre un tapiz de $13 \times 13 \mathrm{~m}$. efectuando una coreografía de ejercicios sin aparatos basados en la ejecución de movimientos corporales y elementos técnicos 
durante 2'15"-2'45” siguiendo los requerimientos del Reglamento y sobre una base musical. Aunque hay una finalidad competitiva, se trata de un deporte de colaboración y sin oposición donde el trabajo en grupo está por encima de los logros individuales (IFAGG, 2012).

Los movimientos fluyen naturalmente de un movimiento al siguiente como si hubiesen sido creados por el movimiento previo (IFAGG, 2012). Todos los movimientos deben ser realizados con fluidez, mostrando la amplitud y variedad en la dinámica y velocidad. El éxito se consigue con el alto grado de sincronización en la coreografía entre los gimnastas, su distribución correcta en el espacio, la expresión conceptual y emocional equitativa, así como el "dibujo" preciso de las composiciones.

Los elementos técnicos escogidos en la composición deben corresponder al nivel físico y la maestría de habilidades y edad de los gimnastas. La GEG combina los elementos gimnásticos básicos como son equilibrios, saltos, giros, elementos acrobáticos sencillos, con elementos corporales más ligados a la danza, tales como ondas, swings, desplazamientos, pasos a dos, y se introducen las elevaciones de uno o varios gimnastas como elemento no esencial pero dinamizador de la coreografía (figura 3) (Conesa, 2015).

Figura 3. Elevación de una gimnasta dentro de una rutina de Gimnasia Estética de Grupo

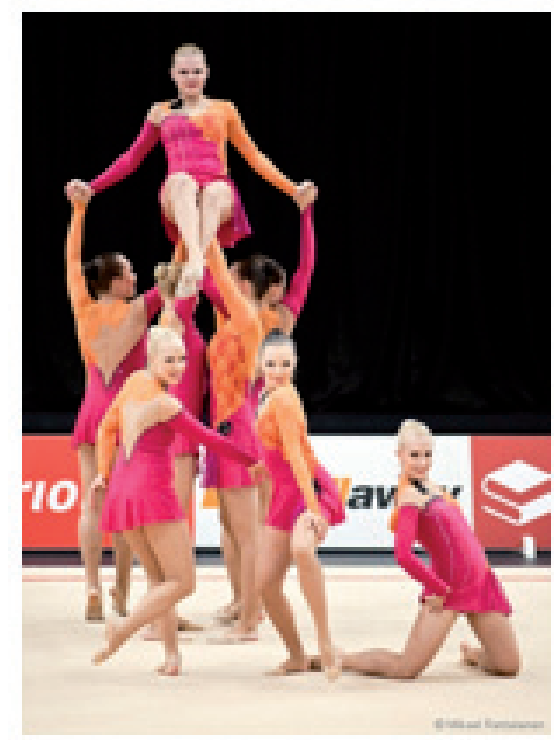

Los contenidos perceptivo-motrices y las habilidades y destrezas básicas que se efectúan en la GEG y que influirán de manera decisiva en la adquisición de la correcta postura, se desarrollan mediante el trabajo específico sobre el esquema corporal, a través de la percepción del propio cuerpo (tonicidad, postura, equilibrio) y la percepción del entorno (estructuración espacio-temporal, lateralidad y ritmo); de la coor- dinación de los patrones motores básicos (desplazamientos, saltos, giros, equilibrios) y de las cualidades físicas básicas, destacando la flexibilidad y la fuerza muscular como factor importante en el mantenimiento de una postura correcta (Martínez-Gallego, 2004).

El modo de competir consiste en desarrollar una pequeña historia coreografiada, sustentada por la expresividad, algunas acrobacias y acompañada de un tema musical. El objetivo es transmitir emoción y sentimientos al espectador a través del movimiento, buscando la armonía, la estética y la belleza del mismo (Miroshnychenko y Martínez-Gallego, 2013).

La GEG aparece en nuestro país para solventar uno de los problemas que tiene la Gimnasia Rítmica Deportiva como deporte, y es que la carrera deportiva de los gimnastas es relativamente corta. Las niñas o niños empiezan a practicar este deporte a temprana edad y en muchos casos tienen que abandonarla al entrar en la adolescencia (Fasting, Pfister y Vázquez, 2000; Fernández, 2001). Lo que se pretende conseguir promocionando la Gimnasia Estética de Grupo es incidir en su aspecto saludable, alargando la vida competitiva de los gimnastas. A diferencia de otras modalidades gimnásticas donde las exigencias de amplitud de movimiento rebasan los límites y grados de normalidad de las articulaciones, acortando las posibilidades de longevidad de los gimnastas en competición (Conesa, 2015). La GEG va dirigida especialmente a los gimnastas de mayor edad para que puedan mantenerse en la competición y alargar su vida deportiva, ya que su nivel de exigencia física y de amplitud de movimiento es menor que en otras modalidades gimnásticas.

El Reglamento Internacional por el que se rige este deporte tiene como objetivo prioritario respetar las etapas de desarrollo de los deportistas El tipo y el nivel de dificultades que se exigen están divididos en categorías, así se dispone de un reglamento específico para edades infantiles de 8 a 14 años y un reglamento específico para las categorías Junior y Senior. En estos Reglamentos se observa la progresión de la dificultad exigida en relación a la maduración de las estructuras corporales fisiológicas y psicológicas adaptadas al esfuerzo del entrenamiento y relacionadas directamente con el trabajo bilateral de los segmentos corporales.

Los grados de flexo-extensión de las articulaciones solicitadas en las dificultades corporales exigidas, concuerdan con los rangos de normalidad establecidos en los manuales científico-médicos (Conesa, 2015). Existen limitaciones en el uso de acrobacias y cargas que posibilitan esos beneficios para la salud de los gimnastas, especialmente en el reglamento Infantil. Se exige que los gimnastas muestren un control muscular bilateral en todos los grupos corporales obligatorios, variando el uso de los elementos, las direcciones y los planos del movimiento, evitando lesiones y descompensaciones (Miroshnychenko y Martínez-Gallego, 2013). 
Análisis de la técnica en gimnasia estética de grupo y sus diferencias con la gimnasia rítmica deportiva

La diferencia entre la GEG y otras modalidades gimnásticas como la GRD se centra en que en GEG predomina la importancia de respetar los movimientos naturales y armónicos del tronco, no debiéndose insistir en los ejercicios que precisan de una hiperextensión de espalda para su correcta ejecución como se exige en GRD (Martínez-Gallego y Rodríguez-García, 2005).

En el reglamento de GEG se recogen penalizaciones que otorga la juez de valoración artística referida a la correcta técnica de ejecución de equilibrios, saltos y flexiones y extensiones del tronco. Las dificultades corporales exigidas respetan los grados naturales de flexo-extensión del tronco no permitiendo grandes hiperextensiones del mismo. En el reglamento Infantil dirigido a la competición de nińos entre 8 y 14 ańos indica prohibiciones expresas de movimientos que pueden causar lesiones y suponen sobrecargas en un aparato locomotor inmaduro (IFAGG, 2012).

La metodología para el trabajo de la flexibilidad en GEG es diferente a la GRD donde se exigen ejercicios concretos de hiperextensión de la espalda y las piernas, mientras que en GEG se consideran unos grados de extensión dentro del intervalo normal $\left(135^{\circ}\right.$ piernas y $80^{\circ}$ espalda), recogida en la realización de todos los movimientos corporales, saltos y equilibrios. Se exige lateralidad, control postural y alineación de segmentos, y su mala ejecución o exceso en el uso, será penalizada por las jueces en el apartado correspondiente.

Sería necesario tomar conciencia como entrenadores sobre los elementos de hiperextensión que se realizan con la espalda en niños en edad de crecimiento (figura 4) debido al alto riesgo de lesión que estos provocan, dando prioridad a una mayor variedad de elementos corporales, ejecutados en una postura correcta y que cumplan las exigencias de bilateralidad (Mata, 1999; Martin, Klaus y Klaus, 2001).

Figura 4. Elemento corporal con hiperextensión lumbar.
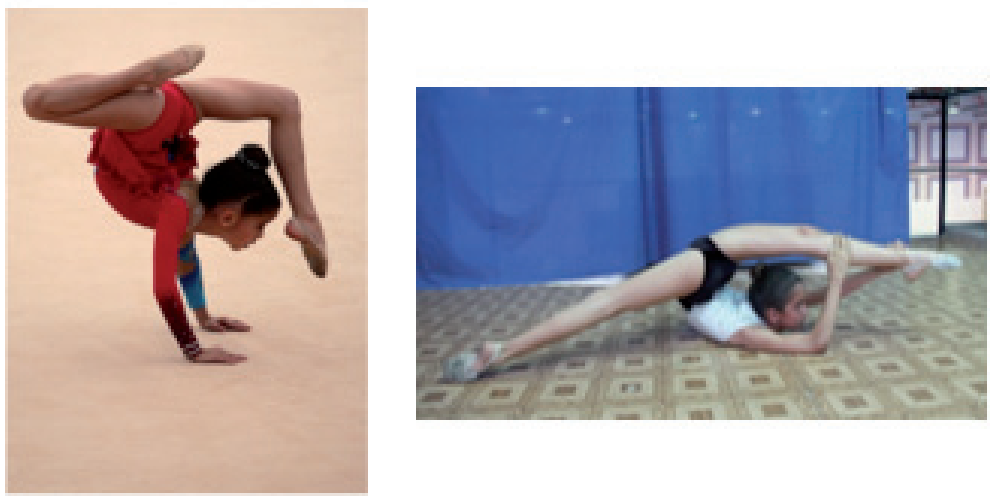

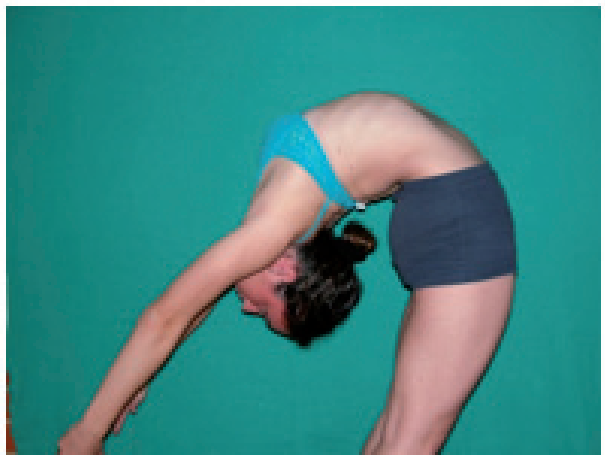

El Reglamento de puntuación de GEG valora tres aspectos diferentes (técnico, artístico y ejecución), otorgándole una puntuación a cada uno de ellos (IFAGG, 2012) La Gimnasia Rítmica Deportiva (GRD) valora 2, uno ejecución y el otro englobaría técnico y artístico, llamado composición (FIG, 2013).

En el VALOR TÉCNICO, los movimientos corporales base de Gimnasia Estética de Grupo, son las ondas y los swings. La característica de estos movimientos es la fluidez con la que se deben ejecutar y esto es uno de los aspectos que lo diferencian de la GRD, en donde el movimiento es más cortante y discontinuo.

En cuanto al VALOR ARTÍSTICO de la composición, destacar que la GEG es una actividad deportiva que requiere una participación bilateral del cuerpo. Se debe hacer que los niños practiquen en igual cantidad e intensidad cada elemento con ambas piernas y brazos, con el propósito de paliar o prevenir futuras lesiones en el raquis (Lisistkaya, 1995). La
GEG respeta los estadios evolutivos y se centra en un desarrollo bilateral de las cualidades coordinativas y de carga físicas. Se ha de proponer a la gimnasta un programa lo más amplio y variado posible de ejercicios, apostando por un trabajo de mayor calidad, globalidad e intensidad. La exigencia de bilateralidad es patente en el Reglamento y las penalizaciones sobre estos aspectos saludables en el valor artístico se encontrarán dentro del apartado de calidad gimnástica, con unas altas penalizaciones si se realizan movimientos prohibidos o existe carencia de trabajo bilateral, con un máximo de deducción de 0.70 .

También existen unas deducciones por error en la composición de 0.10 cada vez en la que se penaliza entre otras cosas que las exigencias de bilateralidad para el grupo no estén claramente presentes (falta de empleo de la pierna no dominante en saltos y equilibrios). La práctica debe ser progresiva y continuada para que los efectos positivos se hagan aparentes, respetando los principios de unidad funcional, así 
como el trabajo bilateral asegurado en GEG por la obligatoriedad de éste en el Reglamento. Los gimnastas deben captar e interpretar las informaciones que reciben, tomar las decisiones adecuadas a los requerimientos del medio, llevar a cabo los movimientos programados y tomar conciencia de lo que hacen y de lo que consiguen a través de la práctica (MartínezGallego, 2014).

Respecto al VALOR de EJECUCIÓN, lo que diferencia claramente a la GEG de la GRD son las penalizaciones sobre aspectos saludables, restando 0.1 por "cada vez" que los hombros y las caderas no estén en línea; la pierna de apoyo esté mal colocada o la forma de cada posición, la postura y las elevaciones estén incorrectamente realizadas.

Los aspectos saludables deben estar representados a través de todos los elementos (equilibrios, saltos y movimientos corporales). En la composición los gimnastas mostrarán el trabajo bilateral del cuerpo con la variedad en el uso de los elementos y el trabajo de flexibilidad.

El reglamento pone especial atención a la progresión en el desarrollo de la técnica para la edad infantil con unos requerimientos adecuados al desarrollo músculo-esquelético de las niñas, y al trabajo dirigido a las mujeres a partir de 16 ańos. La edad media en la competición absoluta internacional oscila entre 25-30 ańos.

Después del análisis de los reglamentos de dos modalidades gimnásticas de gran demanda social, especialmente dirigidas a mujeres, (Gimnasia Estética de Grupo y Gimnasia Rítmica Deportiva), se aprecian claras diferencias que identifican a la Gimnasia Estética de Grupo como un ejercicio físico que incide sobre el bienestar y el mantenimiento de las mujeres en la actividad deportiva saludable para toda la vida.

\section{Bibliografía}

1. Conesa, E. (2015). Valoración de la columna en el plano sagital y extensibilidad isquiosural en Gimnasia Estética de Grupo. [Tesis Doctoral]. Murcia. Universidad de Murcia.

2. Fasting, K., Pfister, G., \& Vázquez, B. (2000). Experiencia y significado del ejercicio físico en la vida de las mujeres de algunos países europeos. Ministerio de Trabajo y Asuntos Sociales: Instituto de la Mujer. Madrid.

3. Fédération Internationale de Gymnastique (FIG) (2013). Recuperado el 15 de junio de 2015 de http://www.fig-gymnastics.com/publicdir/rules/files/rg/RG\%20CoP\%202013-2016_valid\%201st\%20\%20 January\%202015_es_with\%20marks.pdf

4. International Federation of Aesthetic Group Gymnastics (IFAGG) (2012). Recuperado el 10 de septiembre de 2014 de http://www.ifagg. com/wp-content/uploads/2013/10/Competition-rules-2013-2014.pdf

5. Kleenola, I (1996). Naiskliikuntaa. 100 Vuotta. Helsinki: Otava.

6. Langlade, A. \& Langlade, N. (1986). Teoría general de la gimnasia. Editorial Stadium SRL.

7. Martínez-Gallego, F. M. (2004). Disposición del plano sagital y extensibilidad isquiosural en gimnasia rítmica deportiva. [Tesis Doctoral]. Murcia. Universidad de Murcia.

8. Mirosnhychenko, T., \& Martínez-Gallego, F. (2013). Conferencia Cientifica sobre Gimnasia Estética de Grupo. Facultad de Ciencias del Deporte de la Universidad de San Petesburgo.

9. Sierra, E. (2008). La creatividad en la gimnasia estética de grupo. En A. Martínez Vidal y P. Díaz (Coord.), Creatividad y deporte: consideraciones teóricas e investigaciones breves (pp. 185-204). Sevilla: Wanceulen editorial deportiva. 